OPEN ACCESS

ISSN 2528-4649 (online)

ISSN 2338-4409 (print)

*Correspondence:

Rizky Eka Febriansah

rikyfebriyanzah@umsida.ac.id

Received: 26 Desember 2018

Accepted: 26 Desember 2018

Published: 04 Maret 2019

Citation:

Febriansah RE (2019) Pengaruh

Perencanaan Karir terhadap

Komitmen Karir dan Kepuasan Karir

Melalui Pengembangan Karir sebagai

Variabel Intervening.

Jurnal Bisnis, Manajemen dan

Perbankan . 5:1.

doi: http://doi.org/10.21070JBMP.V

\section{Pengaruh Perencanaan Karir terhadap Komitmen Karir dan Kepuasan Karir Melalui Pengembangan Karir sebagai Variabel Intervening}

\author{
Rizky Eka Febriansah* \\ Fakultas Ekonomi dan Bisnis, Universitas Muhammadiyah Sidoarjo, Indonesia
}

The idea of empowering human resources to create the best service for customers can be started through employee's career planning in an organization by using HR practices and policies to develop a variety of mindset, abilities, and competencies with the ultimate goal of acquiring new consumers while maintaining existing customers. This study explores the relationship between career development towards career satisfaction along with career commitment via career development as an intervening variable. The research sample of 37 employees from the Business Service Division of PT Telekomunikasi Indonesia showed that there was a significant relationship amongst career planning along with career satisfaction, career planning along with career commitment, as well as career planning along with career satisfaction through career development.

\begin{abstract}
Keywords: Career development, career satisfaction, career commitment, career planning
Gagasan dari pemberdayaan sumber daya manusia untuk menciptakan pelayanan yang terbaik pada pelanggan dapat dimulai melalui perencanaan karir seorang karyawan di dalam sebuah organisasi dengan menggunakan praktik dan kebijakan SDM untuk mengembangkan berbagai pola pikir, kemampuan, dan kompetensi dengan tujuan akhir untuk memperoleh konsumen yang baru sekaligus mempertahankan pelanggan yang sudah ada. Penelitian ini mengeksplorasi hubungan antara pengembangan karir terhadap kepuasan karir dan komitmen karir melalui pengembangan karir sebagai variabel intervening. Sampel penelitian dari 37 karyawan dari Divisi Business Service PT Telekomunikasi Indonesia memperlihatkan bahwa diperoleh sangkutan yang relevan antara variabel perencanaan karir dengan kepuasan karir, perencanaan karir dengan komitmen karir, serta perencanaan karir dengan kepuasan karir melintasi pengembangan karir.
\end{abstract}

Kata Kunci: Perencanaan karir, komitmen karir, kepuasan karir, pengembangan karir

\section{PENDAHULUAN}

Semakin berkembangnya zaman dan semakin mutakhirnya teknologi, telekomunikasi memiliki peranan yang sangat penting dan strategis pada seluruh aspek kehidupan manusia. Dalam perspektif global, perkembangan teknologi informasi dan komunikasi ini menjadikan dunia semakin sempit karena menghilangkan batas jarakserta menghapus batas negara. Bahkan ruang dan waktu bukan lagi merupakan kendala untuk melakukan komunikasi dengan intens. 
Kebutuhan masyarakat akan pelayanan produk dan jasa telekomunikasi yang semakin meningkat dan beragam memicu pertumbuhan industri telekomunikasi yang begitu pesat di Indonesia. PT. Telekomunikasi (TELKOM)sebagaibadan usaha milik negarapada sektor industri telekomunikasi di Indonesia pun memiliki komitmen untuk memberikan jasa dan pelayanan terbaik bagikonsumen setianya. Hal yang penting dari suatu perusahaan jasa, khususnya jasa telekomunikasi adalah jasa layanan yang diberikan. Salah satu faktor agar karyawan dapat menyampaikan pelayanan yang baik terhadap konsumen ialah jika para karyawan memperoleh moril kerja yang tinggi akibat dari kepuasan karir yang mereka rasakan dalam perusahaan dan saat mereka mempunyai komitmen yang tinggi pada pekerjaannya.

Menurut Arye dan Tan Aryee et al. (1994) menyatakan bahwa kesempatan yang diberikan oleh organisasi untuk berkembang merupakan salah satu faktor terbesar yang berefek terhadap komitmen organisasi. Desain sistem perencanaan dan pengembangan karir yang prima akan berimbas positif sehingga perusahaan dapat menggunakan kekayaan talenta karyawannya untuk penempatan staf dan promosi dengan mencocokkan kemampuan dan minat dari individu untuk pengembangan organisasi. Tambahannya, pengembangan karir membuat perusahaan dapat (1) mengambil keputusan yang tepat disekitar kebijakan mengenai kompensasi finansial dan non finansial organisasi (Kapel \& Sheperd Kapel and Shepherd (2004)), (2) membantu perwujudan rencana manajemen talentaorganisasi untuk merekrut, menjaga, dan memotivasi sumber daya manusia yang ada (Sukoco \& Fadhilah Sukoco and Fadhilah (2016) )serta (3) menghasilkan tenaga kerja yang lebih produktif dan berkomitmen terhadap pekerjaan mereka (Kaye Kaye (2005) ). Menurut penelitian yang dilakukan oleh Baruch Baruch (2001) dalam Adekola Adekola (2011) menunjukan bahwa karir adalah milik individu, akan tetapi dalam penempatan kerja, hal tersebut menjadi kewenangan organisasi untuk merencanakan dan mengelola karir karyawan. Sehingga perencanaan karir organisasi harus juga senantiasa mensinergikan kebutuhan karyawan dan beberapa persyaratan pekerjaan, yang lebih menitikberatkan kepada jenjang atau strata karir tertentu.

Greenberg \& Baron Greenberg and J.A (1993) menyampaikanbagaimana komitmen karir mencerminkanderajat kontribusi dan identifikasi individual dalam pekerjaannya sertamenggambarkan ketidakrelaannya untuk meninggalkan profesi dalam organisasi tersebut. Jadi, komitmen karir dapat dideskripsikanserupa dengan tingkatanketerkaitan individu dalam mengakuibahwa dirinya terikatdengan sebuah pekerjaan atau sebuah jenjang profesipada sebuah organisasi. Granrose \& Portwood Granrose and Portwood (1987) mengungkapkan bahwa lembaga yang menyediakan penerangan karir ke SDM yang dimilikinya serta memberikan bantuan yang relevan bagi karyawannya untuk mencapai karir tersebut, akan mempersempit fokus karir SDM dan mendorong mereka agar lebih loyal dengan lembaga, membentuk komitmen mereka terhadap organisasi. Secara konvensional, kepuasan karir diartikulasikan sebagai suasana emosi yang menggairahkan atau baik yang dihasilkan atas penilaian seseorang mengenai pengalaman kerjanya. Dibutuhkan sebuah karir menajemen saat individu menginginkan memanipulasi situasi karirnya dan membantu mereka mencapai kepuasan karir (Barnett \& Bradley Barnett and Bradley (2007)). Penelitian ini mengembangkan kerangka konseptual dari variabel kunci yang berhubungan dengan kepuasan karir dan komitmen karir, dan mendiskusikan pengujian empirisnya pada konteks karyawan di Indonesia.

\section{METODE}

Gambar 1 menunjukan kerangka konseptual yang nmengilustrasikan hubungan dari variabel. Ilustrasi tersebut menerangkan dimana perencanaan karir mengarah secara langsung terhadap komitmen karir dan kepuasan karir serta mengarah secara tidak langsung pada komitmen karir serta kepuasan karir melewati pengembangan karir selaku variabel intervening.

Statenen di bawah akan menyajikan eksplanasi mendetail mengenai hipotesa

\section{Perencanaan Karir dengan Komitmen Karir}

Penelitian dari Ali Ali (2012) menemukan bahwa individu menjadi secara afektif berkomitmen pada karir yang disediakan oleh perusahaan ketika mereka melihat bahwa perusahaan memberikan jenjang karir yang baik dan membantu mereka dalam konseling perencanaan karir.

Perencanaan Karir dengan Komitmen Karir melalui Pengembangan Karir

Handoko Handoko (2008) memandang bahwa kepuasan karir karyawan lahir dari kondisi internal organisasi yang menggembirakan di sebuah perusahaan, dimana kebijakan serta praktik pengelolaan karir yang dibuat oleh organisasi dapat memuaskan keinginan karir dari karyawan. Adekola Adekola (2011) melalui tulisan yang ia publikasikan juga mensugestikan bahwa pengembangan jenjang karier yang dilakukan oleh organisasi memiliki dampak yang baik dan signifikan terkait dari kepuasan karir karyawannya.

\section{Perencanaan Karir dengan Kepuasan Karir}

Cetak biru perencanaan karir karyawan membuat organisasi lebih mampu mengembangkan dan juga menempatkan personil yang dimilikinya ke sebuah jabatan atau posisi yang singkrom dengan animo, kebutuhan, juga tujuan karir dari individu (Krishernawan Hall and undefined Associates (1986) ). Dimana individu mengerahkan kontrol personal atas karirnya dan terlibat atas pemilihan pekerjaan, organisasi, penugasan tugas, dan pengembangan dirinya kemungkinan besar akan mendapatkan kepuasan karir (Adekola Adekola (2011)).

\section{Perencanaan Karir dengan Kepuasan Karir melalui Pengembangan Karir}

Herzberg, Mausner, \& Sydenham (1959) dalam Draflke Draflke (2008) berpendapat bahwa terdapat beberapa 


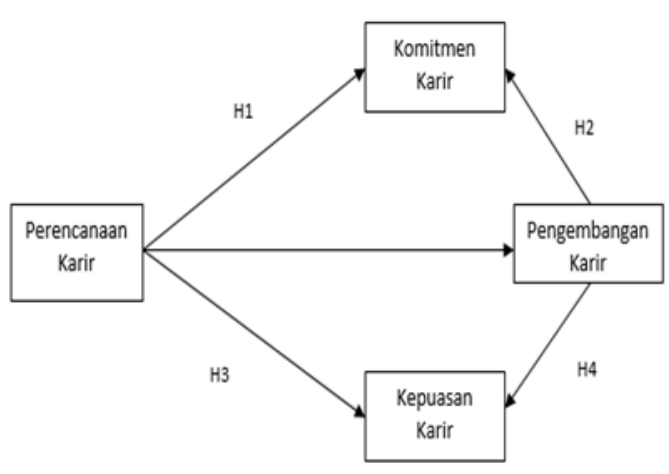

FIGURE 1 | Kerangka Pemikiran

higienis faktor yang diperlukan karyawan untuk merasakan kepuasan dalam karirnya, salah satunya adalah pengakuan di di tempat kerja, lebih jauh Chen, Chang, dan Yeh Chen et al. (2004) mensurvei kapabilitas dari program pengembangan karir dalam mengakui, merespon, dan mensinergikan keinginan karir karyawan terhadap jenjang karir organisasi, memiliki dampak yang positif terhadap kepuasan karir. Salah satu penemuan utama dalam dua penelitian tersebut adalah bahwa perencanaan karir, baik perencanaan personal maupun organizasional, secara positif dan signifikan mempengaruhi tingkat kepuasan karir karyawan.

\section{Perumusan Masalah}

Penelitian ini menginvestigasi pengaruh serentak tentang perencanaan karir pada kepuasan karir dengan komitmen karir serta pengaruh tidak serentak atas pengembangan karir pada kepuasan karir dan komitmen karir.

Hipotesa penelitian:

H1: Perencanaan karir memiliki pengaruh terhadap komitmen karir.

H2: Perencanaan karir memiliki pengaruh terhadap komitmen karir melewati pengembangan karir selaku variabel intervening.

H3: Perencanaan karir memiliki pengaruh terhadap kepuasan karir.

H4: Perencanaan karir memiliki pengaruh terhadap kepuasan karir melewati pengembangan karir sebagai variabel intervening.

\section{Populasi dan Sampel}

Situs penelitian diadakan pada Pulau Bali dengan mengambil objek penelitian Divisi Business Service (DBS) PT Telekomunikasi (TELKOM) area Bali dan Nusa Tenggara. Populasi yang ingin diteliti adalah seluruh personil Divisi Business Service (DBS) PT. Telekomunikasi (TELKOM) Area Bali dan Nusa Tenggara yaitu berjumlah 37 karyawan. Jumlah tersebut hanya mencakup karyawan tetap dikarenakan karyawan tetap mendapatkan peluang akan program pengembangan karir di PT. Telekomunikasi Area Bali dan Nusa Tenggara. Peneliti tidak menggunakan teknik sampling dikarenakan jumlah populasi penelitian yang terlampau sederhana, yaitu hanya sejum- lah 37 orang. Maka dari itu, proses sampling yang dipakai pada penelitian merupakan penelitian sensus.

\section{HASIL DAN PEMBAHASAN}

\section{Pengukuran}

Sebanyak tiga tipe faktor telah ditakar. Pertama adalah menggali informasi mengenai usia. Jenis kelamin, background pendidikan, program pelatihan pengembangan yang pernah diikuti, dan rentang waktu bekerja. Kedua, menimbang respon perseptual attas perencanaan karir dan pengembangan karir. Ketiga dan proses terakhir adalah menilai dua komponen terikat, yakni kepuasan karir dan komitmen karir.

\section{Perencanaan Karir}

Pembahasan yang dilakukandalam menilai variabel perencanaan karir diolah dari dimensi milik King King (1999). Lima skor Likert (sangat tidak setuju = 1 sampai sangat setuju = 5) dimafaatkanpadariset. Sebuah parameter disebutkan telah memenuhi tes validitas Partial Least Square saat mempunyai outer loading melebihi nilai 0,5 sementara tiga (3) artikel persoalan kurang berperan disebabkan oleh outer loading value yang kurang dari 0.5, yaitu parameter X1.4, X1.11, dan $\mathrm{X} 1.12$. Suatu variabel dianggap lolos tes reliabilitas pada PLS jika mempunyai composite reliability value melebihi nilai 0,7 sementara composite reliability value bagi career planning sebesar 0.821 .

\section{Pengembangan Karir}

Pentakaran pengembangan karir diambil dari adaptasi pengukuran milik Gomez-Mejia Gomez-Mejia et al. (2011). Lima skor Likert (sangat tidak setuju = 1 sampai sangat setuju = 5) dimanfaatkan pada riset. Sebuah parameter disebutkan telah memenuhi tes validitas Partial Least Square saat mempunyai outer loading melebihi nilai 0,5 sementara dua (2) artikel persoalan kurang berperan disebabkan oleh outer loading value yang kurang dari 0.5 , yaitu parameter Z6 dan Z9. Suatu variabel dianggap lolos tes reliabilitas pada PLS jika mempunyai composite reliability value melebihi nilai 0,7 sementara composite reliability value bagi career development sebesar 0.813 . 


\section{Komitmen Karir}

Dalam menimbang komitmen karir di riset kali ini, penulismenggunakanperspektifukur yang sebelumnya sudah digunakan oleh Blau Blau (1989). Sebuah parameter disebutkan telah memenuhi tes validitas Partial Least Square saat mempunyai outer loading melebihi nilai 0,5 sementara satu (1) artikel persoalan kurang berperan disebabkan oleh outer loading value yang kurang dari 0.5, yaitu parameter Y1.2. Suatu variabel dianggap lolos tes reliabilitas pada PLS jika mempunyai composite reliability value melebihi nilai 0,7 sementara composite reliability valuedari career comitmentsebesar 0.891 .

Kepuasan Karir

Dalam memperkirakancareer satisfaction, penulis mengembangkan perspektif penilaian yang sebelumnya telahdiujikan oleh Greenhaus, Parasuraman, \& Wormley Greenhaus et al. (1990). Sebuah parameter disebutkan telah memenuhi tes validitas Partial Least Square saat mempunyai outer loading melebihi nilai 0,5 sementara satu (1) artikel persoalan kurang berperan disebabkan oleh outer loading value yang kurang dari 0.5, yaitu parameter Y2.3. Suatu variabel dianggap lolos tes reliabilitas pada PLS jika mempunyai composite reliability value melebihi nilai 0,7 sementara composite reliability value dar career satisfaction sebesar 0.863 .

Hipotesa dalam sebuah penelitian bisa diterima saat skor dari $t$-statistic lebih tinggi dari t-tabel dengan derajat eror setingkat $(\alpha) 5 \%$, yakni sebanyak 1,96. Selanjutnya merupakan nilai path coefficient serta nilai $t$-statistic masing-masing hubungan yang dihasilkan dari analisis:

Sumber: olahan data primer

Berdasarkan hasil analisis pada tabel 1, berikut ini disajikan bahasan pembuktian dari setiap hipotesa:

Hipotesa 1: Pengaruh Perencanaan Karir terhadap Komitmen Karir

Asumsi nilai koefisien atas pengaruh dari Perencanaan Karir terhadap Komitmen Karir menurut tabel satu adalah sebesar 0.361 , serta t-statistik bernilai 2.424 dimana nilai tersebut lebih tinggi dari skor t-tabel sebesar 1.96. Perbandingan tersebut membuktikan bahwa terdapat kosekuensi yang signifikan dan positif pada hubungan antara Perencanaan Karir terhadap Komitmen Karir atas personil SDM yang dijadilkan sampel pada penelitian kali ini. Dapat diartikan bahwa adanya peningkatan pada Perencanaan Karir akan berimbas positif pada penguatan Komitmen Karir dari personil SDM organisasi secara signifikan. Berdasarkan data tersebut, dapat diambil kesimpulan bahwa hipotesis 1 dalam riset ini bisa diterima keabsahannya.

Hipotesa 2: Perencanaan Karir berpengaruh terhadap Komitmen Karir melewati Pengembangan Karir

Imbas mediasi oleh Pengembangan Karir terhadap hubungan dari Perencanaan Karir dengan Komitmen Karir mampu dijelaskan melalui perbandingan nilai dari dampak secara langsung juga dampak secara tidak langsung atas Perencanaan Karir dengan Komitmen Karir. Dengan asumsi bahwa hasil perkalian dari nilai estimasi dampak tak langsung lebih tinggi dari nilai estimasi dampak langsung, maka bisa ditarik kes- impulan bahwa Pengembangan Karir memiliki ciri memediasi hubungan tersebut. selanjutnya akan disajikan mengenai tabel yang mengkalkulasi pengaruh secara langsung dan pengaruh secara tak langsung:

Sumber: olahan data primer

Berlandaskan data tabel yang disajikan diatas, maka dapat ditarik kesimpulan dimana pengaruh secara tak langsung dari perencanaan karir dengan komitmen karir, melalui pengembangan karir, bernilai 0.302. Jika dibandingkan, nilai tersebut lebih kecil dari pengaruh langsungnya yang bernilai 0.287 . Dari hasil tersebut maka dapat dijelaskan mengenai Pengembangan Karir yang memiliki hubungan positif serta signfikan pada hubungan antara Perencanaan Karir terhadap Komitmen Karir pada obyek penelitian yaitu karyawan tetap Divisi Business Service (DBS) PT. Telekomunikasi (TELKOM) Area Bali dan Nusa Tenggara. Hasil perhitungan menyatakan bahwa hipotesis 2 dari penelitian ditolak

Hipotesa 3: Pengaruh Perencanaan Karir terhadap Kepuasan Karir

Asumsi nilai koefisien atas pengaruh dari Perencanaan Karir terhadap Kepuasan Karir menurut tabel satu adalah sebesar 0.371 , serta $\mathrm{t}$-statistik bernilai 2.436 dimana nilai tersebut lebih tinggi dari skor t-tabel sebesar 1.96. Perbandingan tersebut membuktikan jika terjadi kosekuensi yang signifikan serta positif pada hubungan pada Perencanaan Karir terhadap Kepuasan Karir atas personil SDM yang dijadilkan sampel pada penelitian kali ini. Berdasarkan data tersebut, dapat diambil kesimpulan bahwa hipotesis 3 dalam riset ini bisa diterima keabsahannya.

Hipotesa 4: Perencanaan Karir berpengaruh terhadap Kepuasan Karir melewati Pengembangan Karir

Pengaruh mediasi oleh Pengembangan Karir dalam dampak antara Perencanaan Karir dengan Kepuasan Karir mampu dipahami melalui cara perbandingan dampak langsung juga dampak tidak langsung atas Perencanaan Karir terhadap Kepuasan Karir. Dengan asumsi bahwa hasil perkalian dari nilai estimasi dampak tak langsung lebih tinggi dari nilai estimasi dampak langsung, maka bisa ditarik kesimpulan bahwa Pengembangan Karir memiliki ciri memediasi hubungan tersebut. selanjutnya akan disajikan mengenai tabel yang mengkalkulasi pengaruh secara langsung dan pengaruh secara tak langsung:

Sumber: olahan data primer

Berlandaskan data tabel yang disajikan diatas, maka dapat ditarik kesimpulan dimana pengaruh secara tak langsung dari perencanaan karir dengan kepuasan karir, melalui pengembangan karir, bernilai 0.319. Jika dibandingkan, nilai tersebut lebih besar dari pengaruh langsungnya yang bernilai 0.318 . Dari hasil tersebut maka dapat dijelaskan mengenai Pengembangan Karir yang memiliki hubungan positif serta signfikan pada hubungan antara Perencanaan Karir terhadap Kepuasan Karir pada obyek penelitian yaitu karyawan tetap Divisi Business Service (DBS) PT. Telekomunikasi (TELKOM) Area Bali dan Nusa Tenggara. Hasil perhitungan menyatakan bahwa hipotesis 4 dari penelitian diterima. 


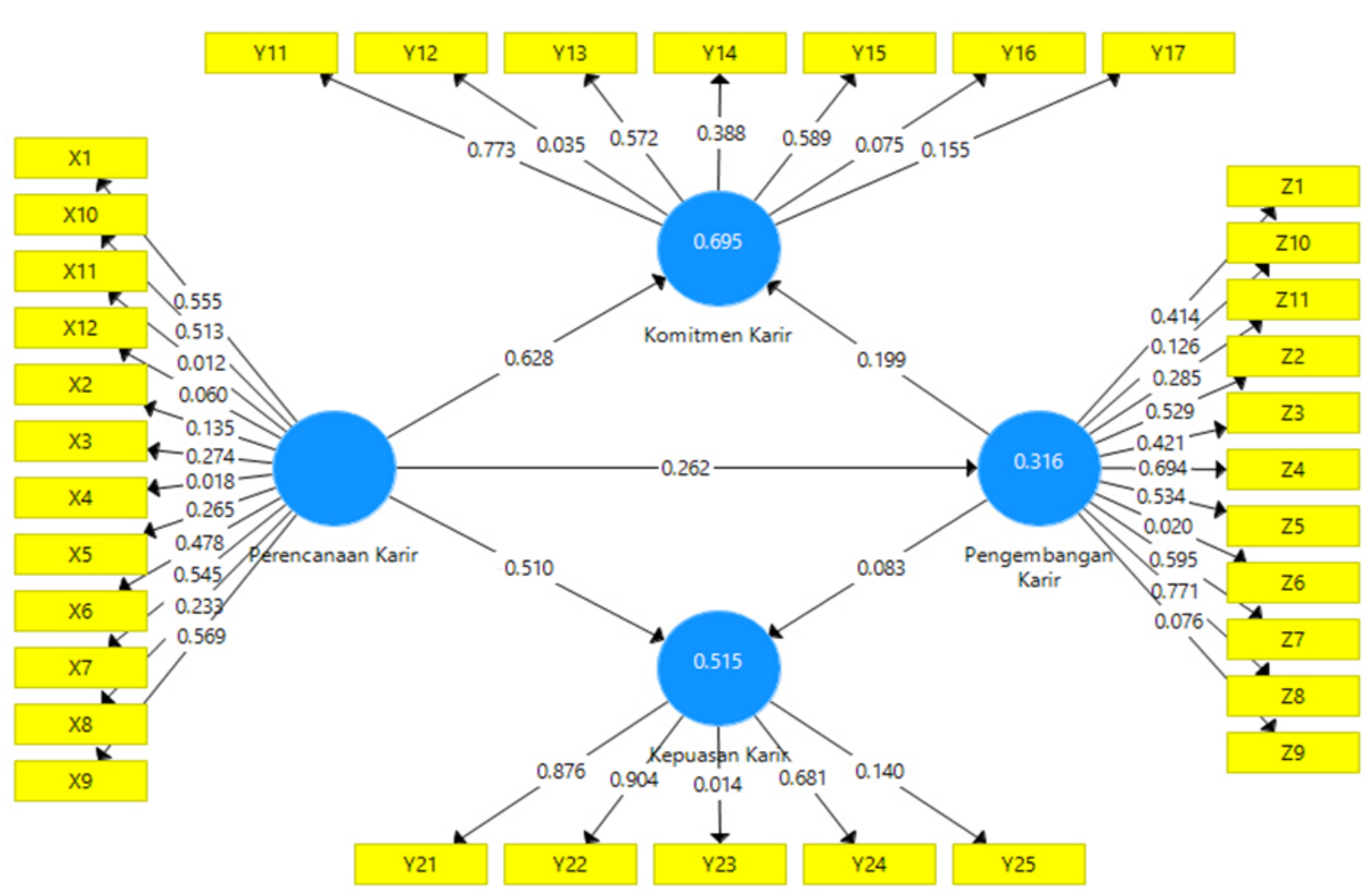

FIGURE 2 | Model Struktural PLS

TABLE 1 | Nilai path coefficient dan t-statistic

\begin{tabular}{lllll}
\hline Num & Pengaruh hubungan & Koefisien & T Statistik & Ket \\
1. & Pengembangan Karir $->$ Komitmen Karier & 0.361 & 2.424 & Signifikan \\
2. & Pengembangan Karir -> Kepuasan Karir & 0.117 & 3.697 & Signifikan \\
3 & Perencanaan Karir -> Komitmen Karir & 0.398 & 2.499 & Signifikan \\
4 & Perencanaan Karir $->$ Kepuasan Karir & 0.371 & 2.436 & Signifikan \\
5 & Perencanaan Karir -> Pengembangan Karir & 0.486 & 5.182 & Signifikan \\
\hline
\end{tabular}

TABLE 2 | Kalkulasi Dampak Langsung serta Dampak takLangsung

\begin{tabular}{lll}
\hline Hubungan & Efek Langsung & Efek Tak langsung \\
Perencanaan Karir -> Komitmen Karir & 0.287 & - \\
Perencanaan Karir -> Pengembangan Karir & 0.582 & - \\
Pengembangan Karir -> Komitmen Karir & 0.519 & - \\
Pengaruh Perencanaan Karir terhadap Komitmen Karir melalui Pengembangan Karir & - & $0.582 \times 0.519=$ \\
& & 0.302 \\
\hline
\end{tabular}

TABLE 3 | Kalkulasi Dampak Langsung serta Dampak takLangsung

\begin{tabular}{lll}
\hline Hubungan & Efek Langsung & Efek Tak langsung \\
Perencanaan Karir -> Kepuasan Karir & 0.318 & - \\
Perencanaan Karir -> Pengembangan Karir & 0.446 & - \\
Pengembangan Karir -> Kepuasan Karir & 0.717 & - \\
Pengaruh Perencanaan Karir terhadap Kepuasan Karir melalui Pengembangan Karir & - & $0.446 \times 0.717=$ \\
& & 0.319 \\
\hline
\end{tabular}




\section{KESIMPULAN}

\section{Pengaruh Perencanaan Karir Terhadap Komitmen Karir}

Ciptaan simpulan dari hasil riset ini menguatkantemuan dari penelitian Ali Ali (2012) yang menemukan bahwa individu menjadi secara afektif berkomitmen pada karir yang disediakan oleh perusahaan ketika mereka melihat bahwa perusahaan memberikan jenjang karir yang baik dan membantu mereka dalam konseling perencanaan karir. Temuan ini juga mendukung pendapat Dessler Dessler (2010) bahwa karyawan akan lebih memiliki komitmen terhadap pekerjaan dan karirnya dalam perusahaan di saat perusahaan juga memberikan perhatian pada perkembangan jenjang karir individu dalam kehidupan kerjanya.Memahami pentingnya perencanaan karir, dianjurkan bagi setiap perusahaan untuk menyediakan kesempatan yang sama bagi setiap karyawan agar mereka dapatmenambah atau memperbaiki akses kemajuan dan perkembangan karirnya. Untuk mengaplikasikan strategi tersebut, perusahaan perlu mengembangkan standar pelatihan dan pendidikan yang jelas serta akses informasi yang berperan untuk menyelaraskan perencanaan karir individu dengan manajemen karir organisasi, yang pada gilirannya meningkatkan komitmen karir karyawan di perusaahaan.

Pengaruh Perencanaan Karir Terhadap Komitmen Karir Melewati Pengembangan Karir Selaku Variabel Intervening

Ciptaan simpulan dari hasil riset ini menunjang hasil dari riset Adekola Adekola (2011) dimana saat tersedianya harapan atas pengembangan karir akan menunjang prakarsa komitmen terhadap karir pada personil SDM organisasi tersebut. Kecenderungan adanya pengaruh yang signifikan disini disebabkan program pengembangan karir yang telah ada mampu menghasilkan komitmen karir pada responden. Faktor lain seperti adanya jenjang karir organisasi yang sesuai dengan minat karyawan kerap menghasilkan komitmen pada karyawan karena karyawan memperspsikan bahwa organisasi peduli terhadap perkembangan karir karyawannya.

Pengaruh Perencanaan Karir Terhadap Kepuasan Karir

\section{REFERENCES}

Adekola, B. (2011). Career Planning and Career Management as Correlates for Career Development and Job Satisfaction. Journal Collage of Management and Social Sciences, Fountain University 1, 100-115

Ali, A. (2012). Analisis Pengaruh Pengembangan Karir Organisasi Terhadap Komitmen Karyawan Pada Kantor Pusat PT. Bank Sulawesi Selatan Barat Kota Makassar

Aryee, S., Chay, Y. W., and Tan, H. H. (1994). An Examination of the Antecedents of Subjective Career Success Among a Managerial Wample in Singapore. Human Relation 47, 487-509

Barnett, B. E. and Bradley, L. (2007). The Impact of Organizational Support for Career Development on Career Satisfaction. Career Development International 12, 617-636

Baruch, Y. (2001). Integrated Career Systems for the 2000s'. International Journal of Manpower 20, 432-457

Blau, G. (1989). Testing Generalisability of a Career Commitment Measure and its Impact on Employee. Turnover, Journal of Vocational Behaviour 35, 88-103

Chen, T. Y., Chang, P. L., and Yeh, C. W. (2004). An Investigation of Career Devel-
Ciptaan simpulan dari hasil riset ini menunjang hasil dari riset Granrose dan Portwood Granrose and Portwood (1987) dimana para peneliti tersebut menegaskanesensi dari perencanaan karir yang berfungsi sebagaifungsipaling awal bagi karyawan untuk mewujudkan kepuasan karir dalam kehidupan kerjanya. Hasil penelitian ini juga mendukung temuan Adekola Adekola (2011) dimana individu mengerahkan kontrol personal atas karirnya dan terlibat atas pemilihan pekerjaan, organisasi, penugasan tugas, dan pengembangan dirinya kemungkinan besar akan mendapatkan kepuasan karir. Kecendrungan adanya pengaruh secara signifikan dari pengembangan karir terhadap kepuasan karir disini terutama pada karyawan yang mampu untuk lebih terlibat dalam merencanakan karir mereka yang masih panjang di dalam organisasi, ke posisi atau jabatan yang sesuai dengan karakter individu dan tujuan akhir karirnya. keterkaitan yang erat dengan kepuasan karir mereka.

Pengaruh Perencanaan Karir Terhadap Kepuasan Karir Melalui Pengembangan Karir Selaku Variabel Intervening

Ciptaan simpulan dari hasil riset ini menunjang hasil dari riset Chen, Chang, dan Yeh Chen et al. (2004) bahwa perencanaan karir, baik perencanaan personal maupun organizasional, yang termasuk dalam program pengembangan karir secara positif mempengaruhi tingkat kepuasan karir karyawan. Kecenderungan adanya pengaruh yang signifikan disini disebabkan adanya persepsi positif dalam pelaksanaan pelatihan, pendidikan dan program mentoring yang telah dilakukan perusahaan. Persepsi positif dihasilkan dari kepuasan karyawan atas keefektifan program pengembangan karir organisasi bagi kemajuan karir karyawan.

\section{UCAPAN TERIMA KASIH}

Kami ucapkan terimakasih kepada rekan-rekan Universitas Muhammadiyah Sidoarjo berkat support nya kami dapat menyelesaikan artikel ini.

opment Programs, Job Satisfaction, Professional Development and Productivity: The Case of Taiwan. Human Resource Development International 7, 441-463

Dessler, G. (2010). Manajemen SDM. Edisi Kesebelas Jilid 1 (Jakarta: Indeks)

Draflke, M. (2008). The Human side of Organization (India: Prentice Hall Ltd)

Gomez-Mejia, L. R., Balkin, D., and Cardy, R. (2011). Managing Human Resources (Canada: Pearson Education)

Granrose, C. S. and Portwood, J. D. (1987). Matching individual career plans and organizational career management. Academy of management Journal 30, 699720

Greenberg, E. R. and J.A, B. (1993). Behavior in Organization (Boston: Allyn and Bacon)

Greenhaus, J. H., Parasuraman, S. J., and Wormley, W. M. (1990). Effects of Race on Organizational Experiences, Job Performance Evaluations, and Career Outcomes. Academy of Management Journal 33, 64-86

Hall, D. T. and undefined Associates (1986). Career Development in Organizations (San Fransisco: Jossey-Bass Publishers)

Handoko, T. H. (2008). Manajemen Personalia dan Sumber Daya Manusia (Yogyakarta: BPFE)

Kapel, C. and Shepherd, C. (2004). Career Ladders Create Common Language for 
Defining Jobs. Canadian HR Reporter 14, 15-16

Kaye, B. (2005). Build a Culture of. Development. Leadership Excelence 22, 18

King, A. S. (1999). Crescendo model of career motivation and commitment: Identity, insight and resilience. International Journal of Value-based Management 12, 29-49

Sukoco and Fadhilah (2016). Analisis Strategi Manajemen Talenta Menggunakan Pendekatan Kompetensi Organisasional Pada Pt Pindad (Persero) Bandung. AdBispreneur 1

Conflict of Interest Statement: The author declare that the research was conducted in the absence of any commercial or financial relationships that could be construed as a potential conflict of interest.

Copyright (๑) 2019 Febriansah. This is an open-access article distributed under the terms of the Creative Commons Attribution License (CC BY). The use, distribution or reproduction in other forums is permitted, provided the original author(s) and the copyright owner(s) are credited and that the original publication in this journal is cited, in accordance with accepted academic practice. No use, distribution or reproduction is permitted which does not comply with these terms. 